\title{
Mujeres y artesanías: Mito y realidad
}

Jasleen Dhamija

Follow this and additional works at: https://knowledgecommons.popcouncil.org/departments_sbsr-pgy

Part of the Entrepreneurial and Small Business Operations Commons, Family, Life Course, and Society Commons, Gender and Sexuality Commons, International Public Health Commons, and the Regional Economics Commons How does access to this work benefit you? Let us know!

\section{Recommended Citation}

Dhamija, Jasleen. 1983. "Mujeres y artesanías: Mito y realidad," SEEDS no. 4. New York: Population Council. 

SEEDS (Semillas) es el nombre de una serie de folletos diseñados con el objeto de responder a las solicitudes recibidas de todo el mundo, pidiendo información sobre ideas de programas prácticos e innovadores en beneficio de las mujeres de ingresos bajos, sugeridas por ellas mismas o por otras personas. Los folletos sirven como medio de compartir tal información y de promover el establecimiento de nuevos proyectos basados en las experiencias positivas de mujeres que trabajan, para ayudarse a símismas y a otras mujeres, a mejorar su situación económica. Los proyectos que se describen en SEEDS, incluida la presente edición, se seleccionan por varias razones: producen dinero en efectivo para las mujeres, las hacen participar en el proceso de la toma de decisiones, especialmente aquéllas que les permiten escoger la forma en que van a percibir sus propios ingresos; se basan en sólidos criterios económicos y han logrado superar con éxito los obstáculos que se encuentran con mayor frecuencia. Estos informes no tienen carácter de preceptos, ya que cada esfuerzo en pro del desarrollo tiene que entendérselas con problemas y recursos diferentes. Lo que tratan de hacer es decribir la historia de un idea y de su realización, en la esperanza de que las lecciones que se aprendan con ella puedan ser útiles en otros lugares y situaciones. También se escriben estos informes para llamar la atención de las personas que ocupan posiciones altas, donde se toman las decisiones, sobre el hecho de que proyectos generadores de ingresos para las mujeres o realizados por ellas, son viables y tienen una función muy importante que desempeñar en la esfera del desarrollo.

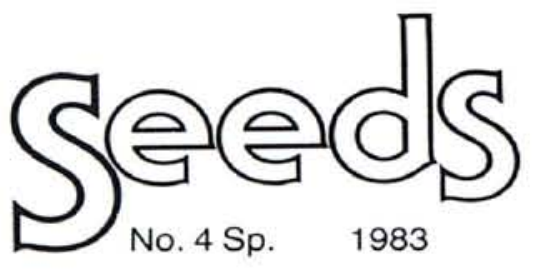




\title{
Mujeres y Artesanías: Mito y Realidad
}

\author{
Relato de Jasleen Dhamija
}

\section{Introducción}

Cada vez que los planificadores, los encargados de preparar programas y los directores de proyectos consideran la cuestion de "cómo desarrollar actividades factibles que generen ingresos para las mujeres", lo primero que les viene a la mente son las artesanias. El mito es que éstas son una ocupación femenina - algo que ellas hacen bien. que, se presume, no interfiere con su trabajo doméstico, que requiere una inversión muy baja y un periodo corto de gestación. Muy rara vez alguien se molesta en analizar la realidad de la situación, desde el punto de vista de la industria de las artesanias o de la vida de las mujeres que el proyecto se propone beneficiar. Son pocos los planificadores o las personas que trabajan en los programas que se dan cuenta de que la manufactura de artesanias requiere conocimientos especializados y, con frecuencia, años de aprendizaje. ¡Tampoco se detienen a pensar que las artesanias que producen ingresos razonables, se han convertido en dominio exclusivo de los hombres!

Este folleto tiene por objeto analizar las artesanias como medio de crear ingresos para las mujeres. En algunos casos constituyen fuente sólida de ganancia; también pueden servirles de nexo con su propia herencia cultural. En la mayoria de los casos, sin embargo, las artesanias hacen que las mujeres se dediquen a un tipo de ocupación que requiere una labor muy intensa, con la que se las puede explotar y que resulta en entradas minimas por largas horas de trabajo. Es por esto que las personas interesadas en mejorar la situación económica de la mujer, deben preguntarse primero si ocupaciones distintas de las artesanias podrian ser mejores fuentes de ingresos. Deben considerar con sumo cuidado todas las posibilidades existentes. Pero aun en el caso de que decidan que las artesanias son la mejor opción, son muchas las preguntas adicionales que se deben formular antes de iniciar el proyecto. Esperamos que el presente folleto sirva de ayuda en este tipo de esfuerzo. 


\section{Artesanias: ¿En qué consisten?}

Definamos primero las artesanías en la forma como se discuten aqui, es decir, como actividades en las cuales ciertos materiales, herramientas y conocimientos a los que se tiene acceso, unidos a la imaginación y habilidad del artesano, se usan para crear objetos determinados. En algunos países el término artesanías se amplía para abarcar toda actividad en que no se usen procesos mecanizados, por ejemplo, preparación de alimentos y de viandas especiales, así como innumerables trabajos hechos a mano. En el presente folleto nos limitaremos a objetos que sean útiles o tengan valor decorativo, una definición generalmente aceptada en el mundo en desarrollo.

\section{Artes femeninas: División laboral que discrimina contra la mujer}

Los trabajos manuales que más dinero le producen al artesano, por ejemplo, fundición de bronce, grabado de metales, joyeria, talla de piedras preciosas, fabricación de vidrio soplado y de brocados, rara vez los hacen las mujeres. Son habilidades del dominio exclusivo de los hombres, quienes las protegen celosamente. Los padres se las pasan a los hijos. Casi nunca se le enseñan a las hijas, pues se presume que éstas se van a casar, abandonando la casa de sus padres y que por consiguiente pueden impartirlas a su nueva familia. Por lo general las mujeres se dedican a labores asociadas con la vida doméstica y el sostenimiento del hogar. Algunas venden lo que les sobra en el mercado local.

Con mucha frecuencia los tipos de oficio que se enseñan a las mujeres son los que se denominan con el eufemismo de "artes manuales femeninas" porque, de una u otra forma, se relacionan con el hogar. Se cuentan entre ellas las de costura, bordados, crochet, tejidos en dos agujas o en telares manuales, fabricación de cestas y alfombrillas $y$, en algunas partes del mundo, alfareria. Personas que piensan que están capacitándolas en artes nuevas, promueven la enseñanza de métodos especiales de estampado de tela, batik y macramé.

Si examinamos dichas artes, nos damos cuenta de que su "feminidad" consiste primordialmente en el hecho de que, esencialmente, consumen grandes cantidades de tiempo, producen ingresos bajos y no son el tipo de habilidad que puede refinarse para que rinda más económicamente. Muy rara vez sirven de base a la creación de una pequeña industria que ofrezca mayores entradas a las mujeres. Dondequiera que dichas actividades se comercializan, sus aspectos más remunerativos se encomiendan a los varones. Tomemos el caso de la sastreria: lo que mejor se paga es el corte, porque requiere una habilidad especial; en el $90 \%$ de los casos, lo hace un hombre. El trabajo más laborioso y menos remunerativo, tal como puntadas a mano, el acabado y la prendida de los botones se le da a las mujeres a las que se pagan los salarios más bajos.

La comercialización de artes "femeninas" puede ser aún peor. En la India,

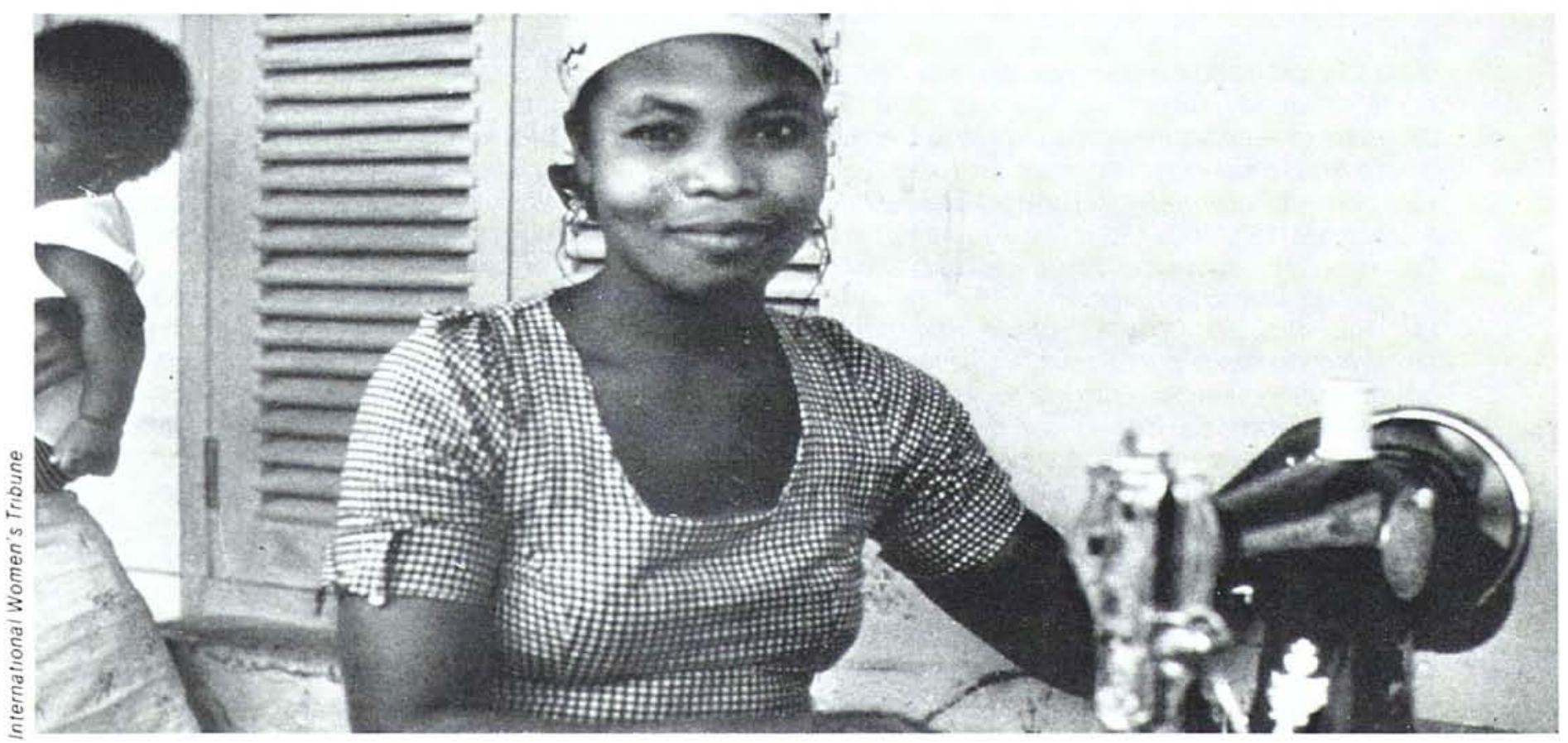




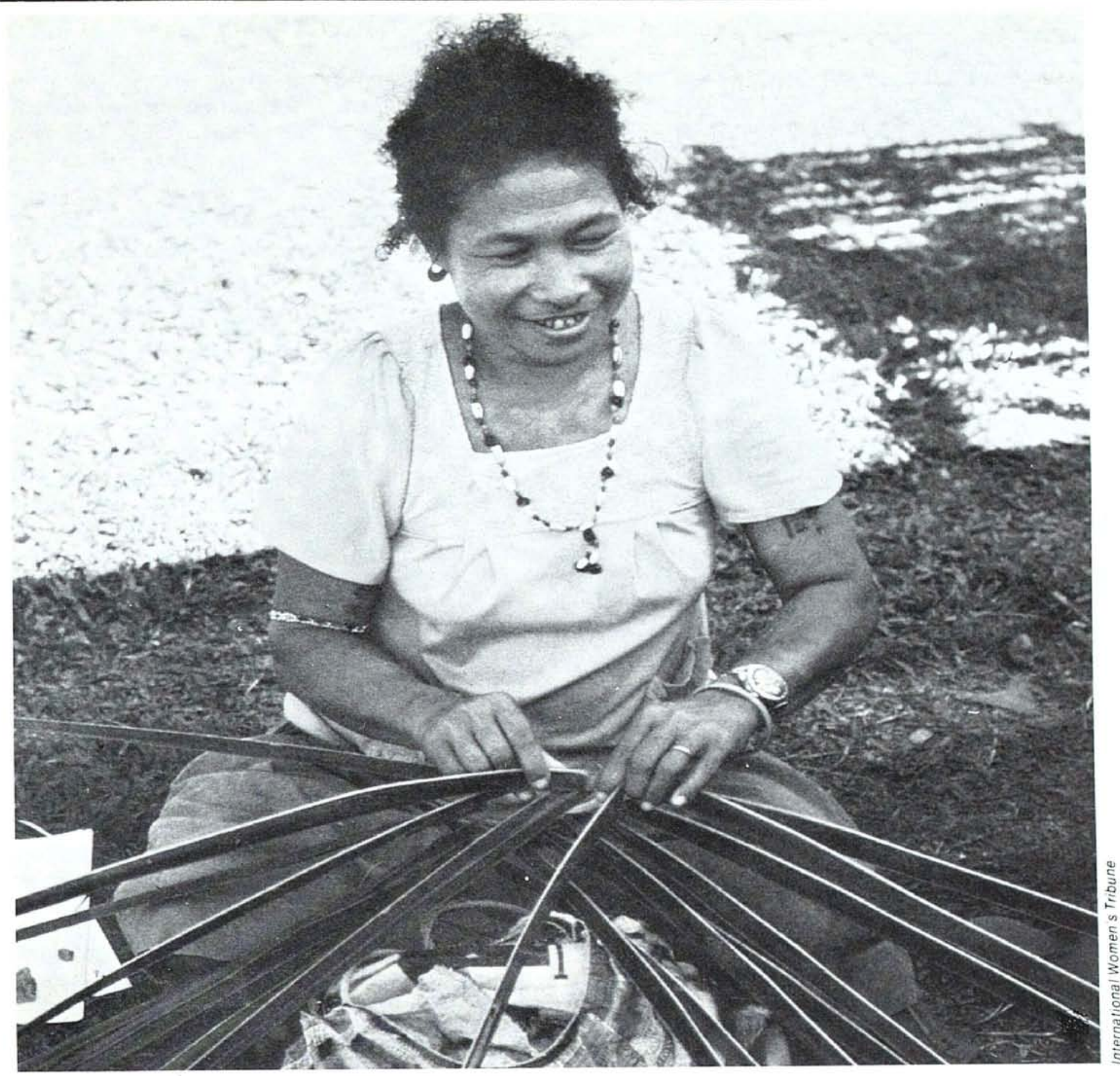

una de las más grandes operaciones comerciales en artesanias es el bordado blanco, hecho en un material muy fino de algodón llamado "chikanwork". Las mujeres que hacen este trabajo pertenecen a la comunidad musulmana y debido a ciertas costumbres sociales viven confinadas en el hogar. Reciben el trabajo de contratistas (intermediarios). Por coser camisas a mano y bordarlas ganan una suma miserable equivalente a 25 centavos de dólar por ocho o diez horas de trabajo. Es un salario de explotación.

\section{Destruyendo mitos y estereotipos laborales}

A pesar de que en muchas sociedades las artes manuales masculinas se distinguen de las femeninas, no existe en realidad un criterio universal sobre el asunto. Lo que es inaceptable en un lugar, bien puede ser práctica aceptada en otro. Por ejemplo, es común pensar que todos los herreros son hombres. Sin embargo, cualquier persona que viaje por el norte de la India ve grupos de mujeres trabajando en herreria, hombro a hombro, martillando en ritmo perfecto los metales con los que se forjan herramientas agrícolas. En la mayoría de los países del Asia la alfareria es un trabajo masculino, pero en casi toda el Africa, es tabú para los hombres, 
hasta el punto de que ni siquiera pueden tocar las herramientas que se emplean en ella. Tradicionalmente se supone que las mujeres son las que tejen; pero en muchos sitios de Africa este trabajo lo hacen los hombres. El delicado y altamente lucrativo trabajo de orfebrería es casi exclusivamente masculino. Sin embargo, se trata de un arte delicado que las mujeres pueden ejecutar con tanta habilidad como los varones. Hoy en dia, uno de los más hábiles joyeros turcomanos de la región del Caspio, en Irán, es una mujer.

La verdad es que la mujeres pueden desempeñar cualquiera de los oficios que hacen los hombres, siempre y cuando se les den las oportunidades y capacitación que necesitan. Si realmente se quieren usar las artesanías como actividades generadoras de ingresos para las mujeres, las distinciones estereotipadas por razones de sexo de que hemos venido hablando, deben desaparecer.

\section{Vida de la mujer campesina}

Antes de planificar cualquier tipo de programa destinado a generar ingresos femeninos, especialmente en la esfera de las artesanias, es indispensable conocer a fondo la vida de las mujeres que participarían en él, a fin de que dicho programa sea en realidad un medio de mejorar la calidad de su vida y no otra penosa tarea que se añadiria a las muchas que ya están obligadas a desempen̄ar.

La mujer campesina es, por lo general, quien atiende las necesidades básicas de la familia. Son muchos los trabajos que tiene que hacer y vive bajo constante presión. Debe acarrear agua desde sitios distantes, conseguir combustible y cultivar y preparar los alimentos que se consumen en el hogar. Las reparaciones menores que se necesitan en la casa son obligación suya; hace vasijas de cualquier material que logra conseguir y pone remiendos en ropas y pieles. La reutilización de artículos usados, o reciclaje, un neologismo muy en boga hoy, es su especialidad. Con vestidos rotos hace parches para cobijas acolchonadas. Los papeles viejos los pulveriza para fabricar vasijas de papier-mache.

Antes de que se puedan desarrollar con eficiencia actividades nuevas destinadas a producir los ingresos en efectivo que tanto necesita la mujer de las zonas rurales, es necesario antes que nada, examinar la totalidad de su vida. ¿Hay alguna manera de aligerar las cargas que lleva? ¿No se deberian atender primero estos problemas? En algunas ocasiones es preciso introducir pequeñas innovaciones, con herramientas y elementos que hacen menos pesado el trabajo de la mujer, a fin de darle el tiempo extra que necesita para dedicarse a actividades generadoras de ingresos.

\section{Lo que se debe y no se debe hacer en la producción de artesanias}

Antes de tratar de establecer cualquier programa de artesanias que ayude a las mujeres a ganar dinero, es absolutamente indispensable, por un lado, examinar qué posibilidades tienen con base en destrezas tradicionales o fáciles de adquirir y, por el otro, estudiar la demanda que exista en ese momento en el mercado local y nacional de las artesanias que se proyecta producir. Igualmente indispensable es considerar la probabilidad de tener que crear y manejar la estructura administrativa que dé al programa el apoyo que necesita. En algunos casos lo indicado pueden ser las artesanías, en otros no. En India, por ejemplo, en donde la mayoría de la población vive en zonas rurales y donde existe una tasa muy alta de desempleo, se ha logrado obtener muy buenos resultados con las artesanias, gracias a una política de protección que se ha venido aplicando por varios años, y a varias formas de asistencia técnica, que incluyen un sistema de comercialización bien establecido, organizado por sectores oficiales y privados. Sin embargo, bien puede ocurrir que las artesanías no sean una estrategia eficaz en otros países con menos habitantes y otras fuentes de empleo. En ciertas regiones de Africa, donde los suelos son fértiles y las mujeres, que tradicionalmente han cultivado $y$ vendido productos agrícolas, tienen libertad de movimiento, las artesanías probablemente no sean la solución que se busca. Allí, métodos mejorados de cultivo y preparación comercial de alimentos podrian ser medios más eficaces de incrementar los ingresos femeninos.

Antes de comenzar a planificar un programa de artesanías es indispensable adelantar un estudio completo sobre su factibilidad.

\section{Estudio de factibilidad}

Lo primero que se debe hacer es considerar la situación total de la economía, el trabajo que ejecutan las mujeres, los materiales de que disponen y los mercados actuales o potenciales que tendrían sus productos. En la 


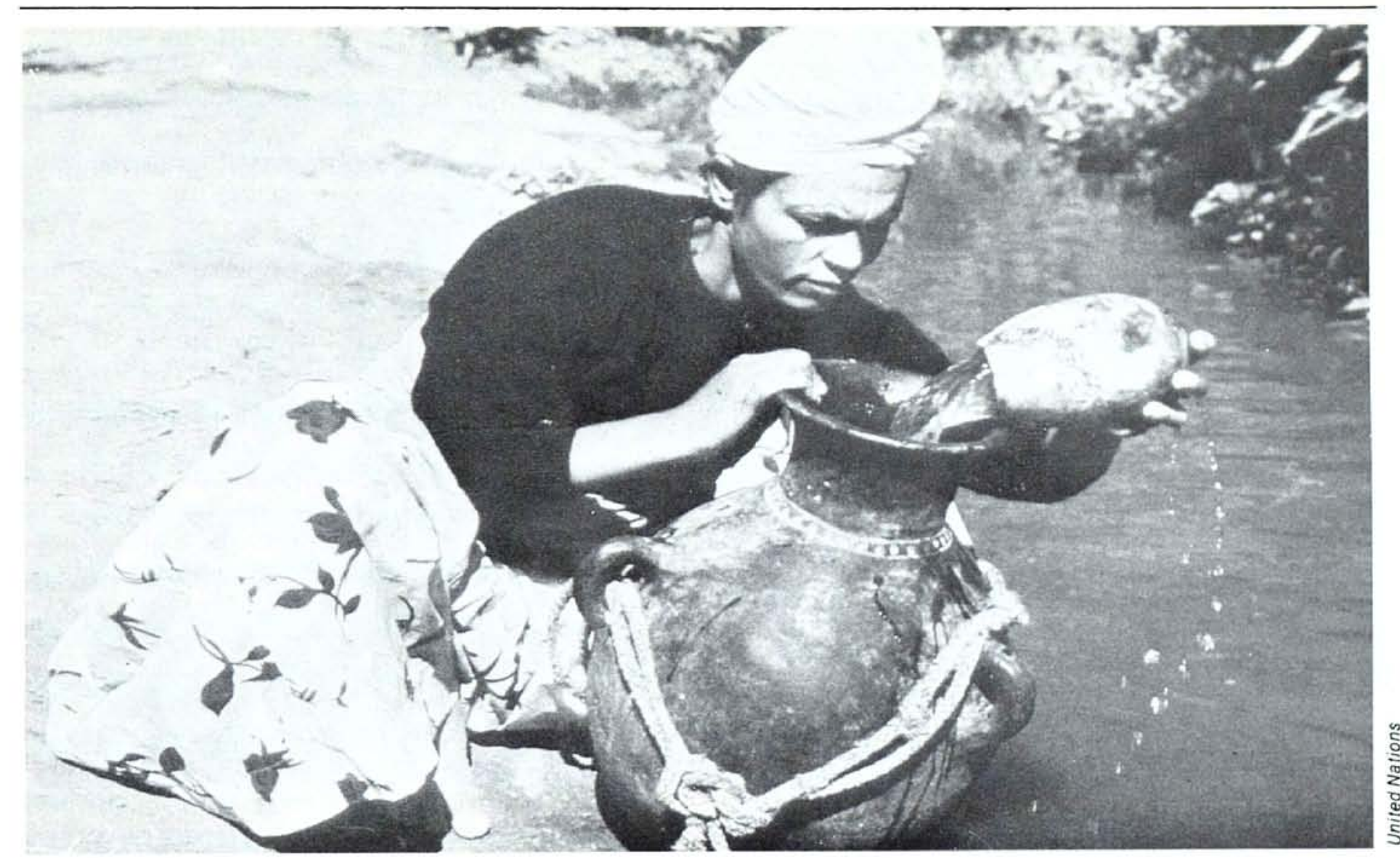

mayoría de los casos esta evaluación debería encomendarse a personas expertas, ya que muchos de los hechos y criterios involucrados en ellas son dificiles, debido a su naturaleza técnica.

He aqui algunas de las preguntas que deben formularse.

\section{SITUACION SOCIOECONOMICA LOCAL}

1. ¿De qué mujeres de dispone para capacitación y trabajo de producción? (edad, residencia, antecedentes culturales, etc.)

2. ¿Qué clase de trabajo hacen las mujeres para ganar dinero? ¿Trabajan fuera de la casa?

3. ¿Qué otra habilidad tienen aparte de las artes manuales, con las que podrian ganar dinero? (Incluyen cualquier destreza que utilizan en ese momento o que hayan dejado de usar).

4. ¿Necesitan esas mujeres ganarse la vida, o percibir solo ingresos complementarios?

\section{DATOS TECNICOS}

5. ¿Cuáles son las técnicas que se usan en la producción? (describa los tipos de tecnología de que se dispone).

6. ¿Cuáles son las materias primas que se van a necesitar para las artesanías? ¿Pueden obtenerse localmente? ¿Cuánto cuestan?

7. ¿Qué otras materias primas se consiguen localmente? ¿Se preparan o utilizan en fábricas de la localidad? ¿Cuánto cuestan?

\section{COMERCIALIZACION}

8. ¿Dónde vende sus productos la gente del lugar? ¿Cómo, cuándo y a qué precio?

9. ¿Cuáles son los precios corrientes de productos similares hechos a mano o en máquina?

10. ¿Se está creando dentro de la comunidad demanda por algún artículo que no producen aún las industrias locales?

11. ¿Qué tanto tiempo tomará adquirir la pericia nueva que se necesita para entrar en producción?

12. ¿Qué mercados se tienen en mente? ¿El local? ¿Uno más amplio en el mismo país? ¿Mercados de exportación? 
Lo que sigue, es el relato de un caso verdadero para el que un estudio de factibilidad, como el mencionado arriba, fue realizado por un consultor experto, contratado por una industria gubernamental que tenía a su cargo un programa de desarrollo rural distinto del puramente agricola. Tuvo lugar en un distrito pobre de Kirman, en Irán. La investigación rápida que se hizo reveló que:

a. Se trataba de una zona con actividad agrícola marginal que dependia de erráticas temporadas de lluvias. Los períodos de inactividad agrícola eran muy largos. Las oportunidades de trabajo fuera de los cultivos eran muy limitadas. Pero todas las familias tenian ovejas que producian lana de buena calidad.

b. Los telares horizontales en que las mujeres tejían pequeñas alfombras eran primitivos. Las alfombrillas eran de mala calidad pero conservaban los diseños tribales tradicionales.

c. Alfombras más viejas, de mejor calidad pero con los mismos diseños, se vendian a muy buen precio en el mercado local de antigüedades.

d. La lana fina de las ovejas se vendia a los negociantes de la ciudad, dejando a los tejedores de Kirman sin materia prima de buena calidad.

e. No existían en el lugar facilidades para teñir la lana.

f. Los pocos telares modernos de la zona pertenececian a los comerciantes. Estos empleaban hombres en la producción de alfombras finas, por las que existía una gran demanda y permitían pagar altos salarios a los tejedores. Algunos de los hombres de la localidad tenian además su propio telar. No solo pericibian un buen salario, sino que participaban en las ganancias de la venta de las alfombras.

El investigador se enteró además de que en unos diez años comenzarian a explotarse las grandes minas de cobre que existian en la región. Indudablemente eso iba a atraer a muchos de los tejedores actuales, y a aumentar además los ingresos de la zona, ampliando así el mercado de las alfombras. Con base en estos conocimientos y en la información contenida en el estudio de factibilidad, se decidió que valía la pena establecer un programa destinado a mejorar la destreza de las tejedoras de alfombras de Kirman.

De lo que se trataba era de ayudarlas a formar una cooperativa mediante la cual pudieran elaborar sus propios tapices. La cooperativa incrementaría su capacidad productiva de la siguiente manera:

- dándoles materias primas de mejor calidad;

- subvencionando el costo de telares nuevos, a fin de que pudieran adquirir sus propios equipos;

- mejorando sus conocimientos sobre tejidos para que pudieran producir sus diseños tradicionales, pero en calidades mucho más finas;

- y por último, enseñarle a las mejores tejedoras cómo utilizar gráficos de patrones y así incluir más colores y diseños nuevos en la manufactura de sus tapetes.

Con la ayuda de organizaciones de economía doméstica se reunió a las mujeres para discutir con ellas el proyecto. Se descubrió que los nuevos telares verticales no cabian en las casas. Los tejados eran muy bajos, además había muy poca luz interior. Como solución a este problema se propuso que el subsidio que se les iba a dar, aparte de cubrir el valor del telar, incluyera además el costo de los materiales necesarios para construir un sencillo cobertizo anexo a la casa, donde dos telares se pudieran instalar, uno a espaldas del otro. El gobierno les suministraría las vigas, los soportes y el latón para el tejado, pero las mujeres, junto con sus familias, se encargarian de construir el cobertizo, como contribución al proyecto.

También subvencionó el gobierno la mitad del costo de los telares y las mujeres pagaron el resto: diez por ciento como cuota inicial y el resto pagadero en el término de un año, con el dinero que ganaran. Seria factible hacerlo así, porque las ganancias anuales proyectadas eran el triple del valor de los telares. El diez por ciento de la cuota inicial (aproximadamente US\$15) era una suma pequeña que las mujeres podian reunir dentro de la propia familia. Así lo hicieron con enorme entusiasmo, ya que el hecho de ser dueñas del telar les facilitaría tener acceso a créditos en la economia local.

Recibieron luego materias primas de las cooperativas locales, asi como instrucción sobre diseños y control de calidad. Un maestro tejedor les enseñó cómo colocar la urdimbre en los telares nuevos, cómo comenzar a usarlos, inspeccionando luego su trabajo periódicamente. El maestro vivia en el pueblo de manera que las tejedoras podían consul- 


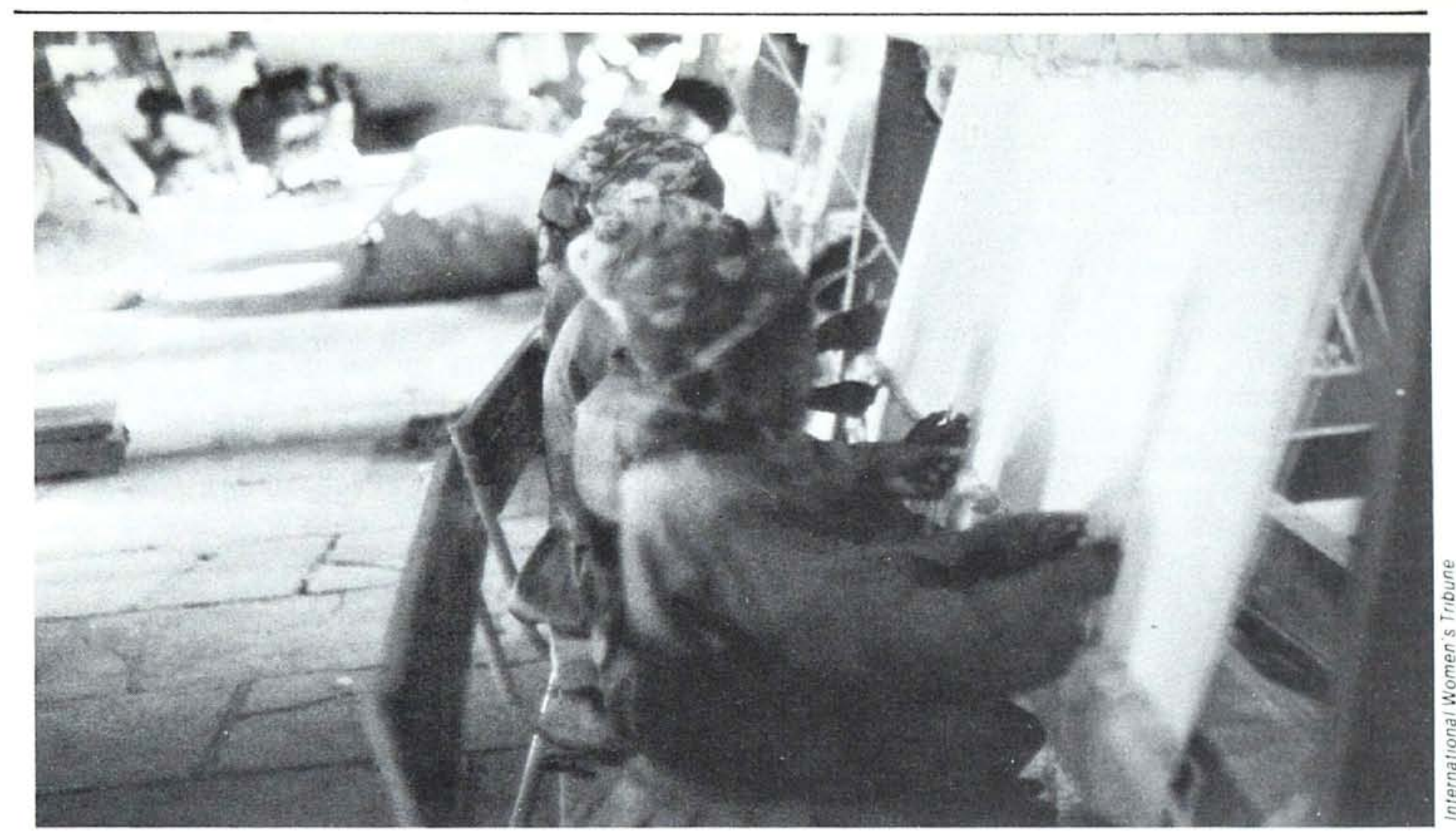

tarle las dificultades que se les presentaban. Cada uno de estos maestros podía fácilmente supervisar el trabajo de quince telares. Mientras progresaba la hechura de las alfombras, la cooperativa otorgaba a las tejedoras préstamos suficientes para comprar lo que necesitaban diariamente. Artículos como harina, sal, aceite, té, azúcar y lentejas con los que ellas contribuyen generalmente al sostenimiento de la familia.

Una vez terminada la alfombra, a la que habia dedicado de tres a siete meses de trabajo, la tejedora podía vendérsela a la cooperativa, a un comerciante, o a cualquier persona que le ofreciera un precio mejor. La cooperativa calculaba el costo básico de la alfombra y se lo pagaba a la tejedora tan pronto como la terminaba. Enseguida, un experto determinaba su valor real, es decir, el precio de venta. Por lo general era más alto que el costo básico. En ese caso, el $50 \%$ de la diferencia entre el precio de venta y el costo básico, se le daba a la tejedora. Este método de pago les sirvió de incentivo para producir tapetes más finos y, poco a poco, involucrarse más y más en todo el proceso de la producción. Más adelante, negociantes privados decidieron que podian confiar más en las mujeres que en los hombres, pues ellas cumplian sus promesas y trabajaban más regularmente. Paulatinamente estos mismos negociantes fueron induciendo a las mujeres de distritos vecinos a que se dedicaran a tejer alfombras finas. A este proceso contribuyó el hecho de que los hombres habian comenzado a emigrar hacia las ciudades en busca de mejores oportunidades de trabajo.

Este proyecto dio buenos resultados porque se basó en una evaluación cuidadosa de las condiciones socioeconómicas existentes, así como de la mano de obra y las materias primas de que se disponía en la localidad. También, porque había una fuerte demanda del producto. La oportunidad de comprar sus propios telares, junto con la instrucción y supervigilancia iniciales que se les dio en forma flexible, permitió a las mujeres entrar a formar parte de una actividad comercial a la que antes solo tenían acceso los varones. Más tarde las tejedoras de Kirman pudieron independizarse del todo de la ayuda gubernamental.

\section{Diversificación de productos}

Otras formas de aumentar ingresos provenientes de la manufactura de artesanías son las siguientes: a) producir artículos nuevos o alterar un articulo tradicional sin cambiar de manera substancial la destreza de quienes los hacen; y b) enseñar oficios nuevos y manufacturar productos nuevos. En ambos casos, el estudio de factibilidad es más importante que nunca. 
Un ejemplo de cómo introducir artículos nuevos o mejorar los que se producen ya, utilizando la misma destreza manual que existe. nos llega de un pueblecito de alfareros en la India, donde por muchos años, las familias habian hecho vasijas para agua con destino al mercado local. Las ganancias de toda la familia por este trabajo nunca pasó de seis dólares semanales. La introducción de articulos nuevos para un mercado más moderno - candeleros, linternas para jardines, lámparas y pedestales pequeños perforados - en cuya manufactura los artesanos usaban la habilidad que ya poseían, no solo les trajo nuevos clientes sino que les permitió cobrar más por su trabajo e incrementar sus ingresos.

Otro caso es el de unas mujeres turcomanas que hacian telas de seda muy linda, pero muy angosta para la que solo existía un limitado mercado local. Cambiando el ancho y los peines de los telares, pudieron producir seda de 90 centímetros de ancho para la que sí existía una demanda creciente. En esta forma triplicaron sus ganacias. En este caso, un gasto nominal muy bajo y alrededor de una semana de capacitación para aprender a manejar los nuevos telares, revivieron un arte manual que estaba a punto de desaparecer, y dieron a muchas de las tejedoras del pueblo una fuente regular de ingresos.

Hay otros casos además en que la habilidad manual se puede reorientar hacia nuevos renglones de producción para los que existe mayor demanda. Hace poco se inició en Etiopia un proyecto destinado a utilizar la destreza de unas alfareras tradicionales, que hacian vasijas de almacenamiento y ollas para la cocina, en la manufactura de materiales nativos de construcción tales como ladrillos, baldosas, tubería y tinajas grandes. Con ello se suplió la demanda local de materiales de construcción y se reemplazaron las láminas de latón y asbestos que se importaban. Sin este cambio, estas alfareras se hubieran visto en poco tiempo compitiendo con los productos de industrias nuevas de materiales plásticos y aluminio prensado, que fabrican vasijas de almacenamiento y utensilios de cocina irrompibles y más livianos.

La segunda manera de diversificar la producción es con la introducción de nuevas habilidades y nuevos materiales. Como ejemplos de capacitación de la mujer en artes manuales que no había practicado nunca, pueden citarse la de cristal recortado en la India, textiles estampados con retícula en Kenya y estampados con bloques manuales, en combinación con encajes teñidos de acuerdo con la técnica del batik, en Etiopía.

La introducción de productos nuevos requiere por lo general capacitar a las mujeres en habilidades que no poseen, invertir sumas substanciales en equipo nuevo, recurrir a métodos de tanteo en la producción, y a sistemas de inspección cuidadosa, etc. Es algo que no se debe hacer a menos que las artesanias que existen ya sean nulas y no se puedan mejorar. Es totalmente indispensable que el estudio de factibilidad se haga con sumo cuidado, prestando atención especial al análisis de mercados, la disponibilidad de materias primas, la pericia técnica y los sistemas de inspección que se van a necesitar.

Siempre que sea posible, se deben utilizar materiales baratos que se consiguen localmente. En Bangladesh, el uso de simples fibras de yute para manufacturar colgaderos de vasijas, bolsas y gran variedad de artículos utilitarios, iniciado por una empresa cooperativa organizada con el fin de rehabilitar a las mujeres que quedaron viudas a consecuencia de la guerra, ha tenido un éxito sin precedentes. Por otro lado, la utilización de materiales importados para producir artesanías, generalmente fracasa. Un ejemplo de este tipo de fiasco, en la introducción de un arte manual y de materiales nuevos, ocurrió en Ghana, en relación con la lucrativa industria tradicional de las flores artificiales. Este proyecto fracasó porque el material sintético que se importaba a precios muy altos, se dañaba con la humedad del clima. ¡El resultado fueron flores artificiales que se marchitaban antes que las naturales!

\section{Comercialización}

La comercialización es un elemento crítico en cualquier proyecto de artesanías. Los problemas de mercados han plagado la mayoria de los programas de esta clase, establecidos por organizaciones de bienestar social en el mundo en desarrollo. Con frecuencia, dichas organizaciones deciden comenzar un proyecto de artesanías en algún sitio, sin analizar primero cuestiones como los requerimientos de los consumidores, la habilidad manual de que se dispone, y a la existencia de mercados o de canales de distribución de los productos. Es imperativo hacer un estudio a fondo de los mercados antes de comenzar cualquier actividad comercial con artesanías. Dicho estudio debe realizarlo un experto.

He aquí algunos aspectos de la comercialización de artesanías que deben tenerse en cuenta cuando se piense establecer una empresa comercial de esta naturaleza: 
a. El artículo que se produzca debe ser de alta calidad. Si el acabado es malo y el artículo no es apropiado para el uso que se le intentó dar, encontrará muy pocos compradores. Es además mala publicidad para el proyecto.

b. Los precios de los productos deben ser competitivos. Un objeto que se vende más barato en otro establecimiento comercial, no atraerá compradores.

c. Deben hacerse siempre pruebas de mercadeo, con muestras de los nuevos productos, antes de proceder a producirlos en grande escala.

d. Hay que alternar los estilos y tener siempre a la mano diseños nuevos que ofrecer. La variedad y el cambio de los productos es fundamental. Hay que mantenerse al dia con las necesidades de los consumidores, para no quedarse con los estantes llenos de objetos que no tienen salida.

La Maendeleo ya Wanawake, una organización femenina de Kenya, con filiales en todo el país, tiene varios grupos trabajando en artesanias. Hace algún tiempo la organización abrió una tienda en Nairobi para vender sus productos. A pesar de estar situada en pleno sector comercial, al frente de un hotel que vive lleno de turistas, no tuvo mucho éxito. No tenía capital de trabajo suficiente para pagar en efectivo por la mercancía en el momento de recibirla de los distintos grupos femeninos. La falta de fondos, le impedía también a la sección de promoción de ventas desarrollar productos y disen̄os nuevos, debido a que no podía suministrar a las artesanas las materias primas necesarias, ni pagarles en efectivo cuando entregaban los productos terminados.

Un organismo regional encargado de ayudar a las mujeres a emprender actividades generadoras de ingresos, analizó la situación y llegó a la conclusión de que los problemas iniciales de la Maendeleo no debian considerarse como un fracaso. Procedió entonces a ayudarla suministrándole capital de trabajo, así como los servicios de un diseñador encargado de la creación de nuevas líneas de productos, y de un trabajador sobre el terreno que tiene a su cargo mejorar la destreza de las artesanas, a fin de que puedan elaborar los nuevos productos. El elemento clave de dicho método de ayuda es un personal técnico competente y bien motivado que está en contacto con las mujeres y les enseña cómo organizarse en asociaciones, cooperativas o grupos privados de producción.

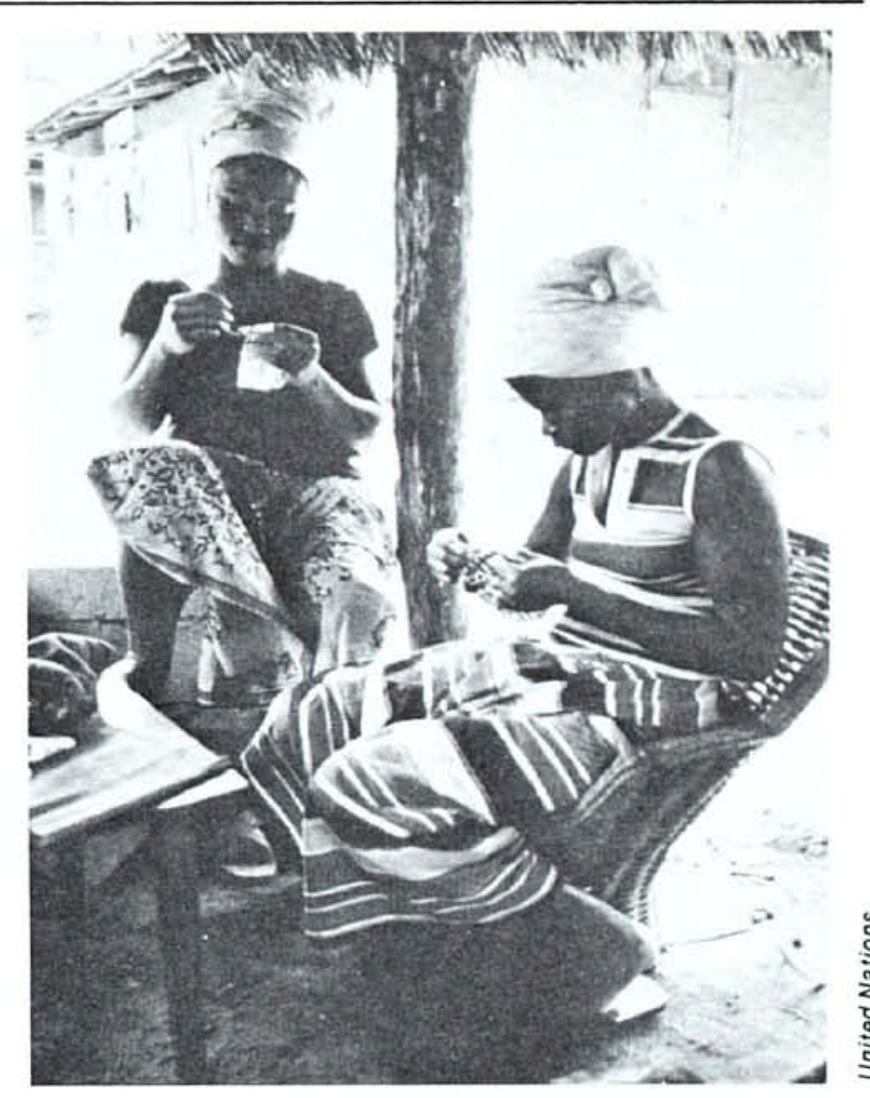

\section{동}

Mientras se diversifican los productos, las mujeres amplían sus habilidades y se obtienen nuevos mercados, es muy importante que no se rompan los nexos con los mercados tradicionales, que son los mercados regulares. Esto ha ocurrido, con muy malas consecuencias, en muchas ocasiones. Dos casos muy conocidos ocurrieron en la India. El primero fue el caso del "madrás sangrante", una tela cuadriculada de algodón llamada "lungi", cuyos colores "sangran" al lavarse y que, por corto tiempo, se puso de moda en Estados Unidos. Cuando esto ocurrió, las cooperativas locales se dedicaron a producirlo, olvidándose del sarong tradicional que usaban los hombres. De repente, al suspenderse la demanda del madrás sangrante en Estados Unidos, las cooperativas se encontraron con existencias enormes de dicho material y sin mercado. Muchas cooperativas se declararon en bancarrota y gran número de tejedores quedaron físicamente sin nada que comer.

El segundo caso fue el de las estatuillas metálicas de deidades, fabricadas por el método de la cera perdida, en un lugar de la India central. Por dos años consecutivos, los fabricantes recibieron pedidos muy grandes del gobierno que estaba interesado en exportarlas. Infortunadamente se olvidaron entre tanto de suplir a la población tribal que habia sido su mercado regular y con la que tenian estrechos nexos culturales. Los vínculos se 


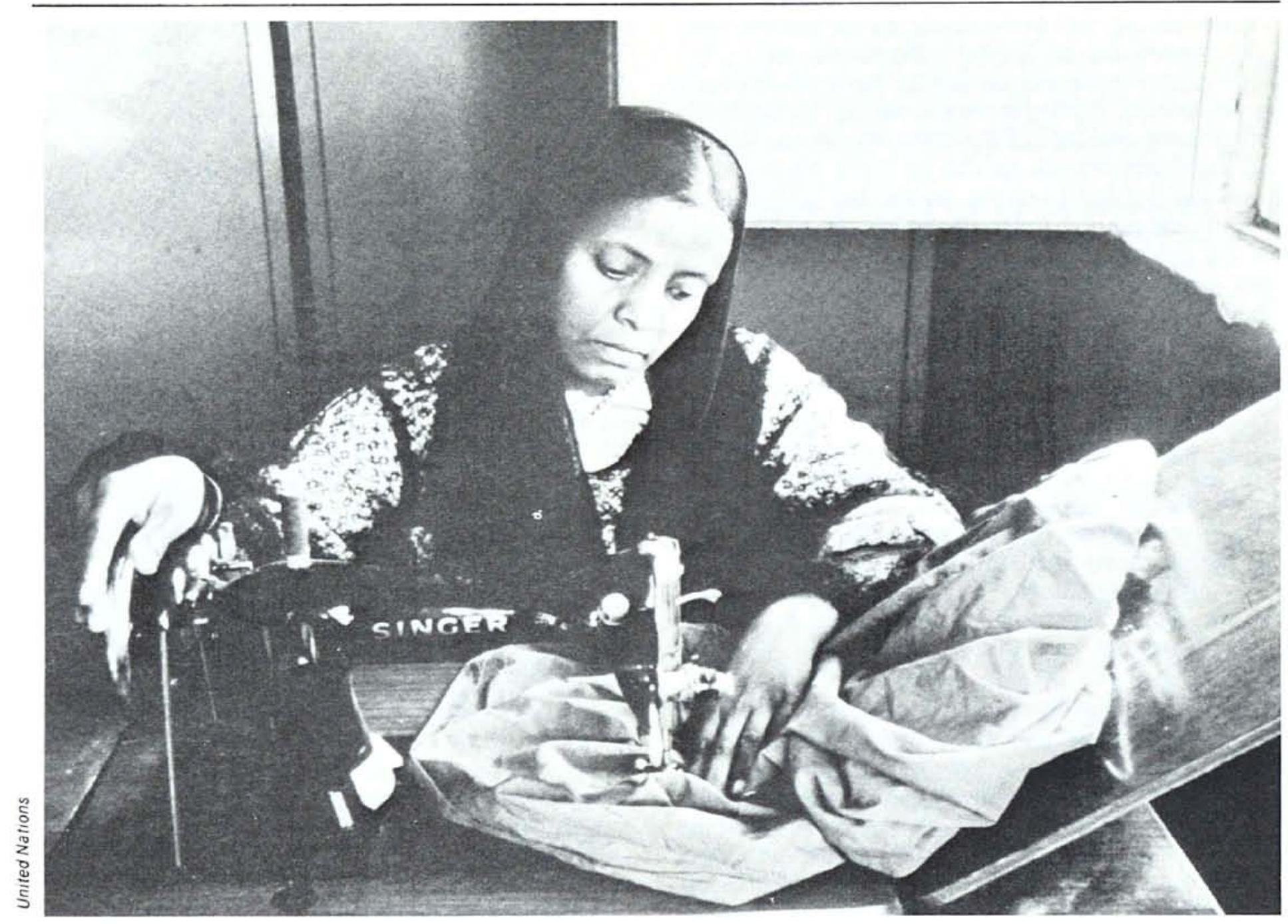

rompieron y cuando el gobierno no hizo pedido alguno en el tercer año, los trabajadores se encontraron con tremendos problemas.

La experiencia ha demostrado que se debe comenzar por encontrar mercados dentro del país, primero cerca de la zona de producción y luego más lejos, en otras ciudades y regiones. Estos mercados locales son sitios naturales de ventas, que ocasionan pocos problemas de transporte y comercialización. Además el mercado doméstico tiene tendencias discernibles que hacen relativamente fácil la tarea de conocer las preferencias de los consumidores. Proporcionan además información inmediata sobre la acogida que tengan las artesanias. Esto ayuda mucho a establecer standards aceptables de producción y de control de calidad.

En cambio, los objetos destinados a la exportación presentan muchos problemas difíciles. Por lo general, se requiere un gran volumen permanente de producción; los diseños y calidad de las mercancias deben satisfacer gustos por lo general desconocidos de personas extrañas, y con frecuencia hay que cumplir complicadas regulaciones gubernamentales, para no mencionar el problema de los transportes. Por todo esto, se requieren recursos financieros de mucha mayor cuantía para organizar con buenos resultados un negocio de exportación a mercados extranjeros.

En el desarrollo de proyectos de comercialización de artesanias, las necesidades de las mujeres tienen prioridad, pero no por ello deben perderse de vista los requerimientos del mercado. Debe mantenerse un buen balance entre la actividad en pro del desarrollo y la operación comercial. Para ello se requiere experiencia administrativa. El conocido Central Cottage Industries Emporium (Emporio Central de Industrias Domésticas), de Nueva Delhi, en la India, es un excelente ejemplo de empresas de este tipo. Fue creado por un grupo de trabajadores sociales bien motivados, con ayuda gubernamental. En forma sistemática estos individuos comenzaron a dar sólidas bases comerciales al negocio. Centros de produción de artesanías, nuevos y viejos, recibieron ayuda para la producción de artesanias nuevas y novedosas. Se establecieron procedimientos de control de 
calidad y se iniciaron campañas de promoción. Gracias a estos esfuerzos, los trabajadores sociales lograron con éxito suministrar trabajo a mujeres de ingresos bajos y producir artículos de la mejor calidad. Su establecimiento de ventas al detal, en Nueva Delhi, es la mejor tienda de artesanias de la India.

\section{Apoyo institucional: Recursos financieros y protección}

En lo que respecta a organizaciones femeninas, bien sean voluntarias o gubernamentales, siempre ha existido la tendencia de organizar las actividades de distintas maneras, sin establecer nexos con instituciones existentes que podrían ayudarlas en el desarrollo de habilidades técnicas comerciales y financieras. La utilización de las mencionadas instituciones existentes puede contribuir al éxito de los programas.

El gobierno de Túnez, por ejemplo, ha adoptado una serie de políticas destinadas a proteger y apoyar industrias pequeñas, como parte de un nuevo plan de descentralización que concede privilegios especiales a empresarios técnicamente calificados. El programa denominado "Producción en Familia", demuestra la forma inteligente en que se aplican dichas políticas. Fue organizado por el Ministerio de Bienestar Social, en estrecha cooperación con el Centro Tunesino de Promoción de Artesanías, otra dependencia del gobierno. Trabajando juntas, las dos instituciones identificaron el tipo de arte manual que se quería desarrollar. Los cursos de capacitación los financió e inició el Ministerio de Bienestar Social. El Centro de Artesanias contribuyó con el instructor, las materias primas y los diseños, asegurando así que la capacitación que se daba a las mujeres alcanzaba el nivel de conocimientos requeridos para una producción comercial.

A las aprendices se les pagó un estipendio durante los nueve meses que duró el aprendizaje, a fin de que pudieran participar en él. Además, el programa de habilitación se organizó en forma de permitirles trabajar independientemente al terminar los cursos. Los nueve meses de enseñanza se dividieron en dos periodos. Durante los cinco primeros, las aprendices trabajaron juntas, en el mismo lugar, bajo la estricta vigilancia del instructor. En los últimos cuatro meses, los equipos y las herramientas se instalaron en su casa, para que aprendieran a trabajar por cuenta propia. Aún hoy, después de independizadas, siguen en contacto con la sección comercial del Centro de Artesanias, y pueden vender sus productos a través de éste, o directamente a los comerciantes. En este caso particular, los nexos con instituciones especializadas ya

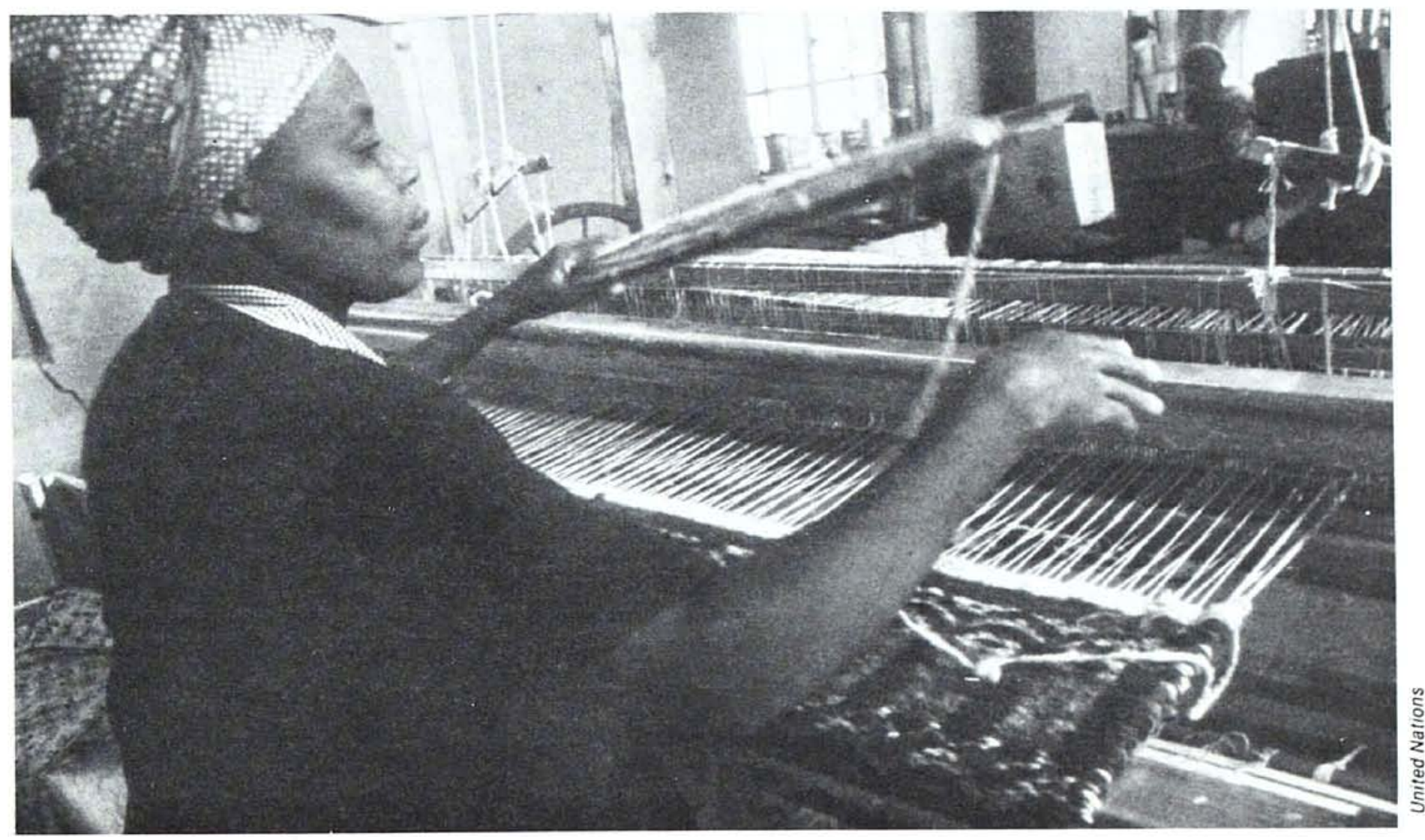


establecidas, protegió al programa contra los fracasos que ocurren con frecuencia por deficiencias en la habilidad de las artesanas y en los métodos de producción, los que, a su turno, ocasionan problemas de mercados y de explotación de las artesanas por parte de los negociantes. Son problemas, es triste reconocer, que son comunes en muchos de los centros de artesanías que se establecen para ayudar a las mujeres.

\section{Estructuración institucional- Dinámica de grupos}

Otro elemento importante en el diseño de programas en que participan las mujeres para beneficio propio, es una organización bien estructurada. Trátese de cooperativas, asociaciones, sociedades registradas legalmente o grupos femeninos tradicionales, es esencial ayudar a las socias a formar una asociación económica viable que las proteja contra la explotación por parte de terceros. Tanto el gobierno como las organizaciones voluntarias pueden canalizar su asistencia hacia grupos organizados, pero no hacia familias dispersas ni hacia individuos. Es más, las asociaciones que están legalmente registradas pueden recibir fondos y conceder préstamos a sus miembros, en términos flexibles. En cambio las condiciones de préstamos otorgados a individuos son con frecuencia más estrictas y requieren la firma de un fiador.

Una de las maneras más eficaces de crear una organización, es fundarla sobre la base de asociaciones femeninas tradicionales. La forma que éstas toman es muy variada. Una de las más comunes es una de ahorros y préstamos como la tontin de las vendedoras de los mercados de Togolandia, o la arisan, en Indonesia. En ambas, las mujeres se reunen regularmente, depositando cada vez una determinada cantidad de dinero. El total de esta suma se presta por rotación a cada una de las socias, permitiéndole a cada una de ellas tener en un momento dado suficiente capital para una inversión grande. Pueden ser reparaciones en la casa, compras al por mayor de mercancía para vender al detal, compra de herramientas, u otro gasto que estaría más allá de la capacidad indivudual de cada una. Cuando grupos como éstos funcionan bien, pueden inclusive servir de garantía a las socias que obtengan préstamos de otras organizaciones. Sirven además como grupos de presión para asegurarse de que los préstamos se reembolsan. Además si una de las mujeres, por alguna circunstancia se ve incapacitada para hacer un pago, las demás pueden unir sus recursos para pagarlo en la fecha especificada.

Infortunadamente, la mayoría de los proyectos en pro del desarrollo pasan por alto los grupos sociales tradicionales, tratando en cambio de crear nuevas estructuras. Por lo general, la aceptación de innovaciones y el éxito a largo plazo de un proyecto son con frecuencia mayores cuando, en vez de nuevas estructuras, se fortalecen las asociaciones ya establecidas a fin de que puedan realizar actividades distintas.

El tipo de estructura institucional que comunmente se establece en conexión con proyectos artesanales, son cooperativas del tipo de las que existen en sociedades desarrolladas. Lo que se hace con esto, es introducir un sistema que requiere un detallado sistema de contabilidad $y$, por ende, un nivel relativamente alto de conocimientos de parte de los dirigentes de la organización. Como gran cantidad de mujeres en muchas partes del mundo son total o parcialmente analfabetas, es frecuente que la dirección de los grupos femeninos quede en manos de hombres que poseen la instrucción que a ellas les falta. De ahi que no sea dificil de entender por qué las socias de tales grupos pierden pronto el interés. Si se quieren usar las cooperativas para ayudar a las mujeres, se necesita, o simplificar los procedimientos, o suministrar experta asistencia administrativa. En Irán, por ejemplo, se contrataron los servicios de un experto en este campo, para que ayudara a organizar y administrar cooperativas de mujeres rurales. El experto asistió a las socias, encargándose de complicados libros de cuentas, de transacciones financieras, de comprar materias primas y vender los artículos terminados. También sirvió de nexo entre la sociedad y la operación de mercadeo de la cooperativa. Este modelo ha tenido mucho éxito en Irán; quizá pueda servir como medio eficaz de suministrar este tipo de ayuda a otros grupos femeninos que la necesiten.

Otro sistema adoptado por algunas cooperativas de artesanias en la India, incluye el suministro de asistencia administrativa al comienzo de la cooperativa y durante los primeros años, después de los cuales se reduce paulatinamente. Se espera que al final de este periodo la cooperativa cuente ya con pericia administrativa o esté en capacidad financiera de contratar un gerente profesional. * Acaso el método más eficiente

-Véase la edición de SEEDS titulada "Cooperativas de Vendedoras de los Mercados: Dan Prestamos a las Mujeres". 

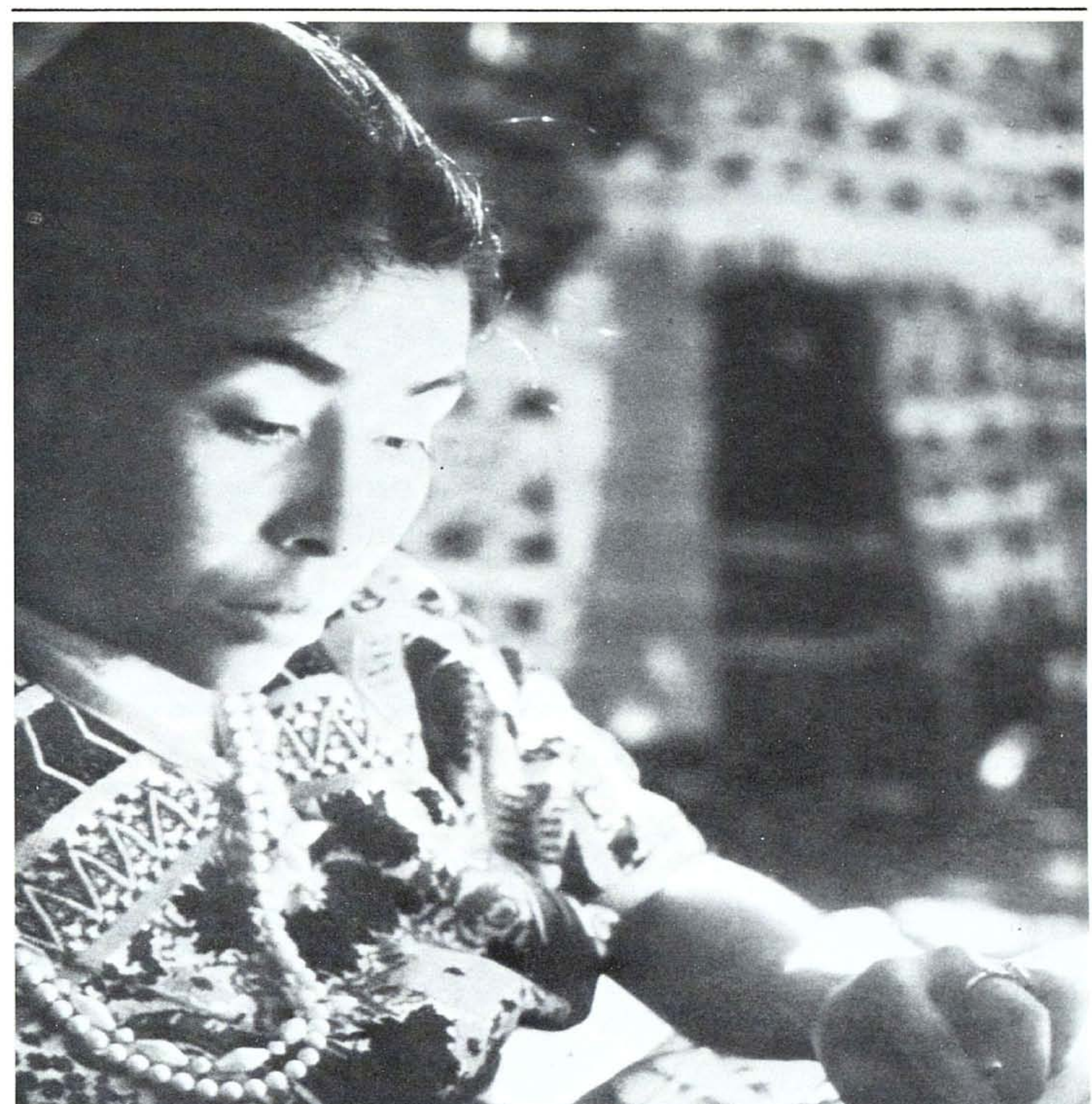

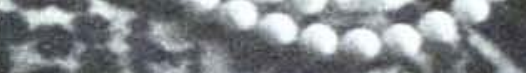

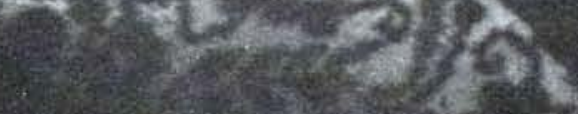


sea una combinación de los dos sistemas anteriores, pero añadiéndole un componente de capacitación para algunas socias que más tarde podrian encargarse de tareas administrativas. Las personas seleccionadas, se someterian a un periodo corto de instrucción intensiva que las prepararía para desempeñar funciones directivas dentro de la organización.

Es necesario hacer hincapié en el hecho de que las cooperativas no son el único tipo adecuado de asociación. Para comenzar, las mujeres pueden optar por una forma de organización menos estructurada. Existen un buen número de formas intermedias de agrupación que pueden dar buenos resultados. Por ejemplo, el arrendamiento de un local o la compra de materiales en forma colectiva, $u$ organizaciones estructuradas de manera que puedan suministrar a las socias un salario fijo $y$, además, darles oportunidad de participar en las ganancias. La estructura que se establezca debe ser la que más convenga a las necesidades y recursos de los miembros de la organización.

Debe recordarse también que las asociaciones femeninas no son solo un medio de organizar empresas comerciales, sino que tienen una función social: hacer que las socias se sientan parte de la comunidad. En lugares donde las costumbres sociales no le permiten a la mujer participar en actividades que se realicen fuera del hogar, o en las que participen los hombres, las asociaciones femeninas pueden ser el primer paso que de hacia el mundo exterior. Allí puede encontrar otras mujeres con experiencias de vida diferentes y participar en actividades que la saquen del ambiente enclaustrado en que frecuentemente vive.

\section{Conclusiones}

Las artesanías pueden servir de medio de incrementar los ingresos femeninos en ciertos lugares, pero solo en las condiciones que se describen en las páginas anteriores, por tratarse de una ocupación especializada, con pequeños mercados y de potencialidad limitada en cuanto a empleo se refiere. En los siguientes puntos se resumen algunas de las cuestiones claves a las que se debe prestar atención siempre que se considere un programa femenino de artesanías:

1. Las Ilamadas artesanías "femeninas" consumen cantidades de tiempo, pagan poco y ofrecen poca posibilidad de mejorar la destreza de la mujer.

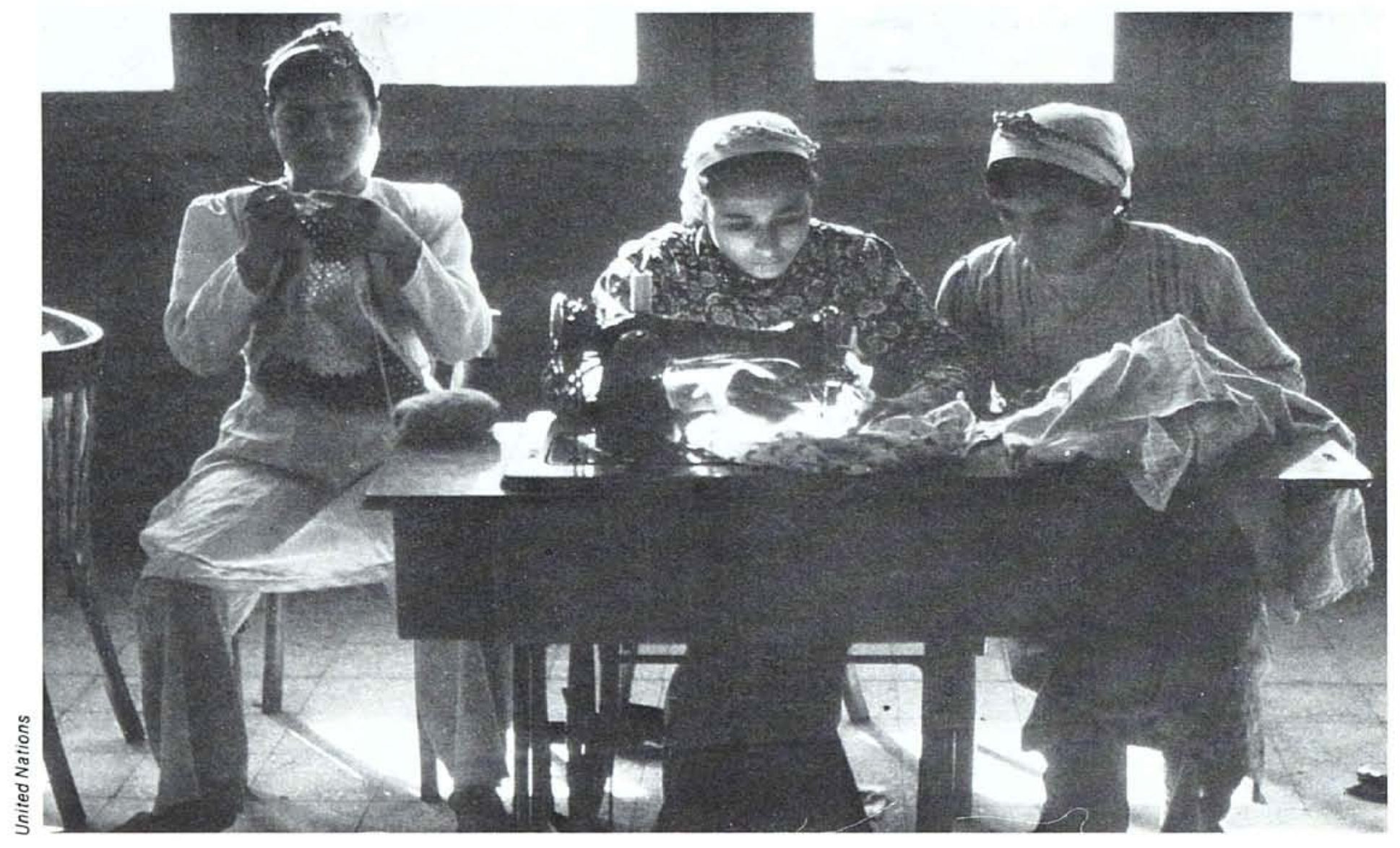




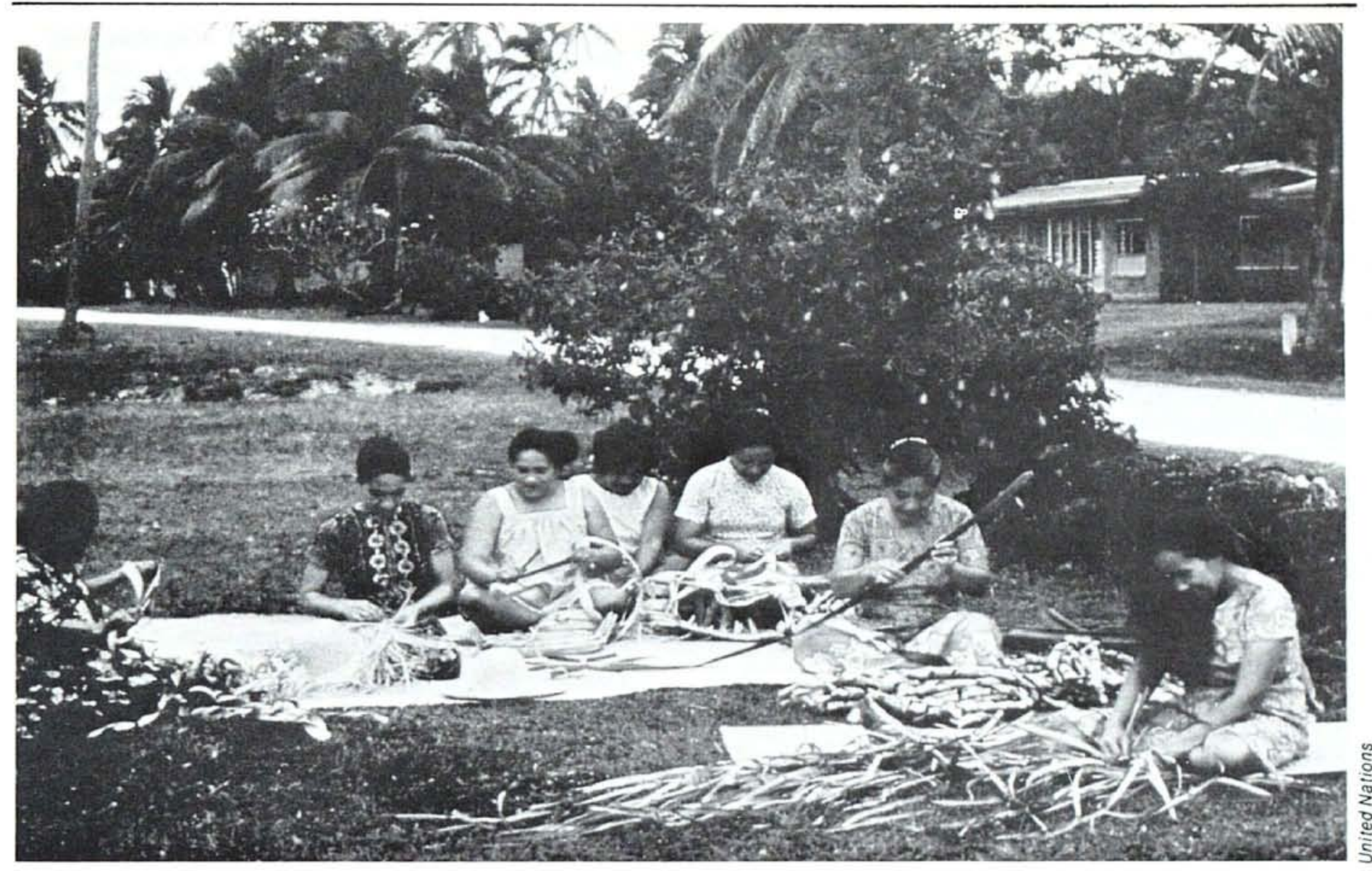

2. De ahí que antes de embarcarse en un proyecto de artesanías, sea indispensable estudiar en qué condiciones trabajan en ese momento las mujeres que se quiere beneficiar, las oportunidades que se les podrian presentar con las habilidades que posean ya o que sean fáciles de adquirir, y las posibilidades que existen de crear y manejar la estructura administrativa que necesita el proyecto. Hay que recordar que las artesanias son por lo general un método más complicado de generar ingresos para las mujeres que otras ocupaciones, como la de preparar alimentos para el mercado local.

3. Hay que pensar en forma imaginativa respecto a la manera como se pueden generar ingresos para las mujeres. ¡Ellas pueden realizar las mismas tareas que ejecutan los hombres, si se las capacita y se les da acceso a las oportunidades de empleo!

4. Es indispensable hacer un estudio a fondo del mercado, antes de iniciar cualquier actividad de carácter comercial.
5. Las conexiones con el mercado tradicional-que es el mercado regularno deben romperse mientras se investigan otras plazas de venta para los productos.

6. Los elementos claves para el éxito de un proyecto son un personal técnico bien motivado y competente y una gerencia capaz de dar orientación adecuada al grupo, ayudarle a diversificar la producción, mejorar la calidad de las artesanias $y$ tener acceso permanente a los mercados.

Siempre que se trate de artesanias hay que actuar con extrema cautela. Si bien es cierto que pueden suministrar ingresos viables, las artesanias se pueden utilizar también como medio de explotación, sirviendo únicamente para hacer aún más pesada la carga que soportan las mujeres, y privándolas además de cualquier oportunidad de mejorar su posición económica y social. 


\section{APENDICE}

A continuación se indican varias fuentes de

información sobre programs regionales de artesanías, que cuentan con asistencia técnica.

\section{Organizaciones regionales que suministran asistencia técnica}

\section{AFRICA}

African Training and Research Centre for Women (ATRCW) United Nations Economic Commission for Africa

P.O. Box 3001

Addis Ababa, Ethiopia

Atención: Mary Tadesse

\section{ASIA}

Women's Programme Centre

ESCAP

U.N. Building

Rajdamnarn Avenue

Bangkok, Thailand

Atención: Daw Awe

All India Handicrafts Board

Government of India

Ramakrishna Puram

New Delhi, India

\section{AMERICA LATINA}

Sección de Programas Femeninos

CEPAL

Casilla 179/D

Santiago, Chile

Atención: Erma García-Schfardet

\section{ZONA DEL CARIBE}

Women in Development Unit

Extra-Mural Centre

University of the West Indies

Pinelands

St. Michael, Barbados

Atención: Peggy Antrobus

Women in Development

6 Bartletts

Christ Church, Barbados

Atención: Lynn Allison

\section{INTERNACIONAL}

International Labour Organization

$\mathrm{CH} 1211$

Geneva 22, Switzerland

International Trade Centre

$\mathrm{CH} 1211$

Geneva 22, Switzerland

World Crafts Council

20 West 55 Street

New York, N.Y. 10019 USA

\section{Asistencia técnica-Consultores}

Consultants in Development

2130 P Street, N.W.

Suite 803

Washington, D.C. 20037

Atención: Maryanne Dulansey

\section{Publicaciones}

"Third World Producers Guide to Alternative Marketing", por David Dichter

Para información escribase a:

David Dichter \& Associates

9 Rue de Vermont

1202 Geneva, Switzerland

"Notes on the International Workshop on Alternative Marketing Organizations and Third World Producers" (Sept. 3-8, 1976. Países Bajos)

Para información escríbase a:

Stichting Ontwikkelings Samenwerking

Kerkrade-Nederland

Holzstraat 19

Consultants in Development (CID)

Publicaciones:

"Expansión del mercado externo para las artesanías del tercer mundo: El papel de las organizaciones del mercado alternativo." 1976 (Español, inglés y francés)

"Formulario para evaluar la factibilidad de desarrollar una pequeña industria." 1977. revisado en 1982 (Español, inglés, francés)

"Formulario describiendo un producto ofrecido al mercado exterior." (Español, inglés, francés)

"Mannuel, seminaire/atelier sur l'artisanat" (Francés)

Todas las publicaciones del CID están a la venta. En algunos casos se facilitan a programas del tercer mundo, a cambio de otras publicaciones, pero siempre a discreción del CID.

Para información escríbase a:

Maryanne Dulansey

Consultants in Development

2130 P. Street, N.W.

Washington, D.C. 20037 USA 
Diseño: John Cotterman

Tipografía: Village Type \& Graphics

Foto de la portada: Naciones Unidas

Imprenta: Graphic Impressions, Inc.

Traducción: Myriam Luz

Jasleen Dhamija es actualmente Jefe de la Division de Pequeñas Industrias y Artesanías para la Mujer Africana, un proyecto conjunto de la Organización Internacional del Trabajo y de la Comisión Económica de las Naciones Unidas para Africa. Comenzó su carrera hace 26 años, trabajando en la India en un proyecto pionero, destinado a desarrollar industrias rurales y de artesanias. Trabajo además en Irán durante seis años, en actividades rurales distintas de las agrarias, y en el desarrollo de planes de estudio para cursos de artes aplicadas y de cultura asiática en la Universidad Farabi. Ha estado intimamente asociada con asuntos de desarrollo rural y arte folklórico. Ha escrito varios libros sobre estos temas.

Invitamos a nuestros lectores a que no envien sus comentarios así como ideas para proyectos que puedan incluirse en futuras ediciones de SEEDS. Las personas que deseen recibir ejemplares adicionales de este folleto y que su nombre se incluya en la lista de distribución, pueden dirigirse a:

\author{
Ann Leonard, Directora \\ SEEDS \\ P.O. Box 3923 \\ Grand Central Station
}

New York, N.Y. 10163 U.S.A. 


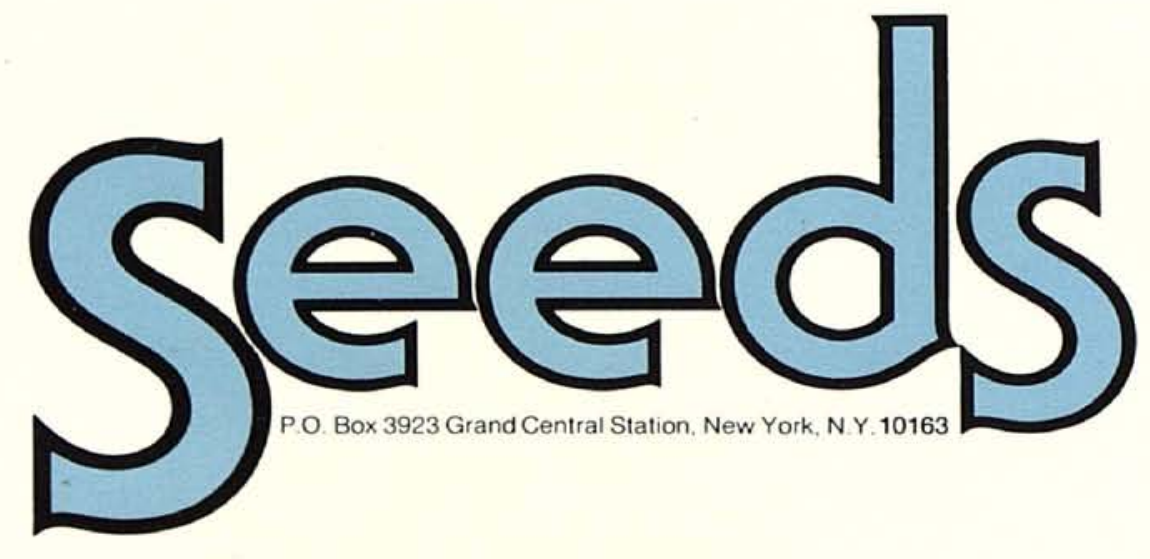

